\title{
Placement of a Double Lumen Endotracheal Tube in Lateral Position for a Video-Assisted Thoracoscopic Surgery- A Case Report
}

\author{
B.M. Munasinghe ${ }^{1 *}$, Nishanthan Subramaniam ${ }^{2}$, Nimalan Srisothinathan ${ }^{3}$, Mario \\ Anandappa $^{4}$ \\ ${ }^{1,2,3,4}$ District General Hospital, Mannar, Sri Lanka
}

\begin{abstract}
Removal of foreign objects from the thoracic cavity could be performed by open or video-assisted surgeries. Anaesthesia for such cases could be demanding which would require one lung ventilation and intubation in unfamiliar positions. Depending on the extent of underlying injuries, sudden haemodynamic collapse should be anticipated, and precautions should be taken to manage such occurrences. We present a unique case of a safely conducted anaesthesia and surgery for a thoracoscopic removal of a long-bladed knife. One lung ventilation with a double lumen endotracheal tube placed at right lateral position in the absence of a fiber-optic bronchoscopy with improvisation using available equipment is described. According to our knowledge, the former has not been reported elsewhere in the literature.
\end{abstract}

Keywords: Video-assisted thoracoscopic surgery, VATS, double lumen tube insertion, lateral intubation, penetrating injury to chest

\section{Introduction}

Even though being a relatively rare form of trauma, thoracic impalement injuries carry high morbidity and mortality. ${ }^{1}$ In cases of retained knife blade injuries, unplanned extractions could lead to massive haemorrhage, hemodynamic collapse and even death. ${ }^{2}$ One-lung-ventilation (OLV) with double lumen endotracheal tubes (DLT) may be required and positioning could prove to be challenging. ${ }^{1}$ We present a case of a safe removal of an impaled knife utilizing a conventional DLT placement in lateral position and video-assisted thoracoscopy (VAT).

\section{Case report}

A 34-year-old previously healthy young male presented to our institution with a retained knife at the back of left upper chest following an assault. A thorough assessment was carried out. He was not

*Correspondence: B.M. Munasinghe

E mail: malakafmp@gmail.com

https://orcid.org/0000-0001-8373-4752

Received: $16 / 12 / 2020$

Accepted: 06/17/2021

DOI: http://doi.org/10.4038/slja.v29i2.8741

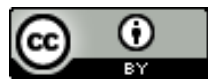

pale, conscious, rational and haemodynamically stable with a pulse rate of $94 \mathrm{bpm}$ and blood pressure of $124 / 76 \mathrm{mmHg}$. He was tachypnoeic with a respiratory rate of 30 per minute with no subcutaneous emphysema. Pneumothorax and haemothorax were excluded by clinical examination, chest radiograph (Figure 1) and ultrasound chest.
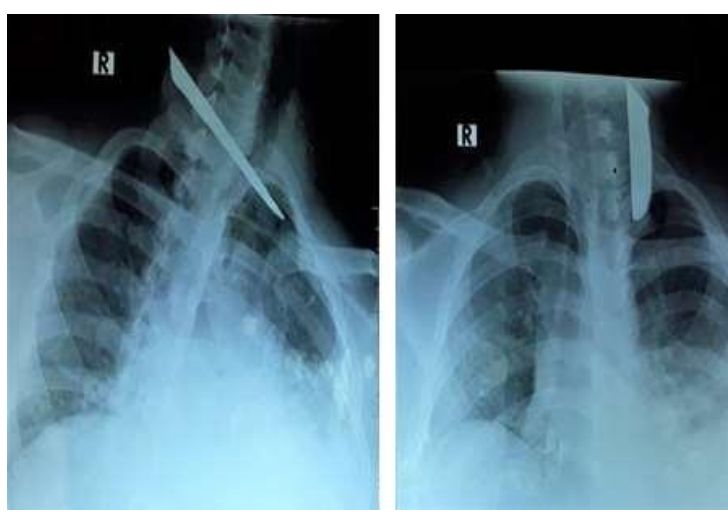

Figure 1. Chest radiograph views: Left lateral, Right- PA. Retained knife entering posteriorly just superior to the first rib in left

He was maintaining a peripheral oxygen saturation of $97 \%$ with supplemental oxygen. There were no other injuries. The airway assessment was not 
predictive of any difficulty. He was kept fasted. Blood was grouped and cross-matched. The nearest computed tomography facility was $100 \mathrm{~km}$ away while the closest thoracic center was located 250 $\mathrm{km}$ away. Collective decision was made for a VAT with OLV, considering the haemodynamic stability and risk of worsening underlying injuries and compromise of haemodynamic parameters during the long road transfer. Risks were explained and informed written consent was taken. Difficult airway trolley was kept ready. Suitable devices required to position the patient supine for the intubation and surgery were not available. A detailed, improvised plan was devised. An adequate-sized gallipot was placed housing the external portion of the knife and secured safely insitu using adhesive plaster. The patient was placed in right lateral position on the operating theatre table with left hemi-thorax in non- dependent position. (Figure 2)

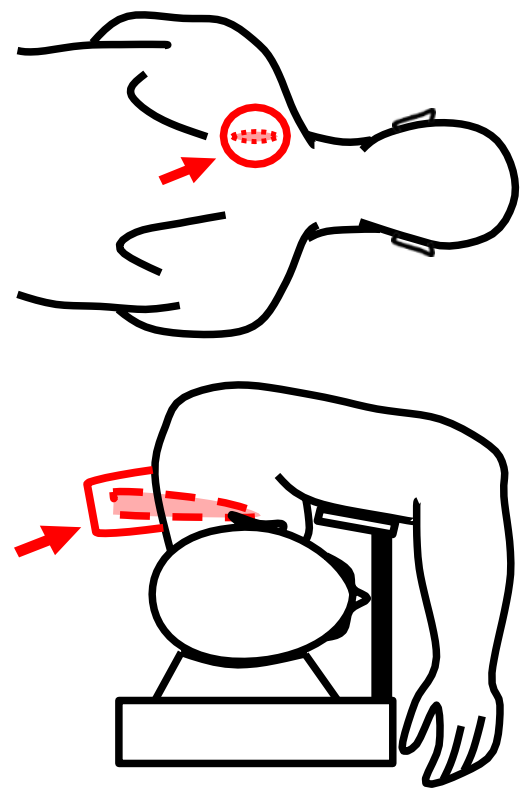

Figure 2. Placement of gallipot (arrow) encasing the part of knife (in broken lines) Top-lateral view, Bottom-cephalic view

The airway plan was briefed with the team which included intubation through a DLT in lateral position. In case of failed intubation, the gallipot was to be used as contingency for changing the position to supine. The team was ready for open thoracotomy in case of surgical necessity. As FOB to ascertain the correct placement of the DLT was unavailable, conventional technique was opted. Following preoxygenation and intravenous induction, a left 39F DLT was placed safely in the first attempt with a Cormack- Lehane grade of 2 . Ultrasound guided left sided internal jugular central line and radial arterial cannula were inserted. Invasive monitoring was commenced. Subsequently, left lung was collapsed. There was no desaturation during OLV and haemodynamics were stable. The knife was found to enter the thoracic cavity posteriorly just above the first rib medial to the medial border of the scapula. It has traversed the thoracic cavity anteriorly piercing the anterior wall at second rib just lateral to the mediastinum (Figure $3)$.

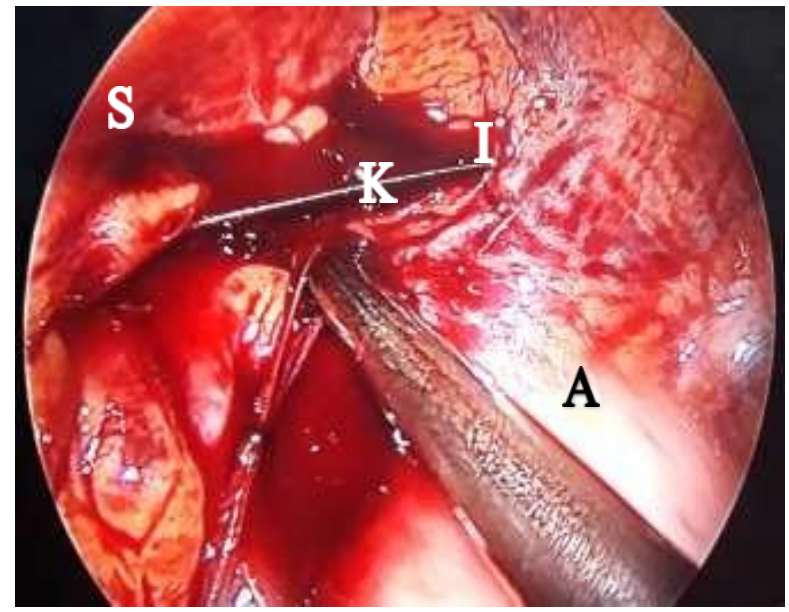

Figure 3. The knife $(K)$ traversing immediately superior to the first rib (not visible) missing subclavian vessels(S), piercing the anterior chest wall (A) with intercostal vessel injury (I)

Radial arterial pressure was monitored carefully and supra clavicularly, ultrasonic visualization of subclavian vessels was carried out to detect any vascular injury. Under the direct vision, the knife was carefully removed (Figure 4).

Haemostasis of the intercostal vessels was achieved by diathermy. Injuries to other vital structures were excluded. At the end, left lung was expanded following placement of an intercostal tube. Arterial blood gas analysis was satisfactory. The patient was extubated and sent to intensive care unit for observation. Pain scores were minimal. He was discharged to ward on day 2 and home on day 6 . 


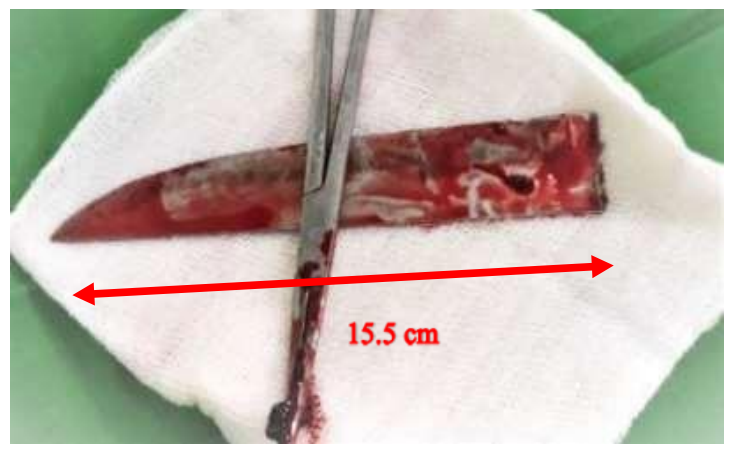

Figure 4. The knife after extraction

\section{Case Discussion}

Thoracic foreign body removal could be done either through open thoracotomy or by thoracoscopy, latter being utilized for haemodynamically stable patients. It has added advantages of panoramic views, reduced pain scores and morbidity. ${ }^{3}$ In cases of retained objects in the thorax, anaesthesia could be challenging due to the need for one lung ventilation, difficulties in positioning ${ }^{3}$ and possible catastrophes such as massive haemorrhage. Patients may have to be positioned laterally, in decubitus position or supine between two stretchers to avoid worsening underlying injuries. When single lung ventilation is demanded, several options are available whereas DLT placement is one of the commonly adopted techniques. Fiber-optic bronchoscope is ideal to confirm the correct placement of a DLT, however, for left sided DLT, auscultation and clamping methods could be sufficient. ${ }^{4}$ Interestingly, after supine placement, positional change has led to migration of the DLT in some cadaveric studies ${ }^{5}$ which could result in iatrogenic airway injuries or hypoxaemia in clinical practice. Literature shows higher failure rates in lateral endotracheal intubations with traditional airway equipment. ${ }^{6,7}$

On the other hand, lateral intubations with the help of intubating LMAs ${ }^{8}$ and optical stylets ${ }^{9}$ were found to be more successful.

In addition to the discussed concerns, the positioning of this patient was also proved to be challenging as the external portion of the knife hindered safe supine positioning for intubation, in the absence of appropriate accessories used during such instances. There is an interesting and very similar case report of a retained knife in the lower thorax. Here, the authors have positioned the patient's upper and lower torso in a surgical trolley and the operating table respectively, with knife in the gap between the two structures. ${ }^{10}$ In our patient, however, this method was precluded as the knife entry point was much higher in the thorax, which could have led to inadequate support and stability of the head and neck and significant strain on the neck and cervical spine. The improvised method (with backup) was devoid of these and led to successful securing of the air way.

The anaesthetist who intubated this patient had experience in lateral intubations with single lumen tubes. Based on the clinical scenario and available skill, lateral DLT placement was favoured here with backup plans for worse case scenarios. The intubation was successful in the first attempt without airway injuries or subsequent mal position.

\section{Conclusion}

Anaesthetists could be presented with emergent need of securing airway in unconventional positions, requiring careful planning and improvisation. While this should be based on available resources and skill, it would be unarguably advantageous specially for the junior anaesthetists to have hands-on experience in intubating at unconventional positions as even with expertise and appropriate equipment, potential for failures are higher compared to conventional positioning. Having backup plans in case of failed intubations and intra and post-operative monitoring for iatrogenic airway injuries are essential.

\section{References}

1. Liu YW, Lee JY, Tsai DL, Kao CN, Chang PC, Chou SH, et al. Survival of the fittest: The role of video-assisted thoracoscopic surgery in thoracic impalement injuries. J Thorac Dis. 2018 Jul 1;10 (7):4445-52.

https://doi.org/10.21037/jtd.2018.06.133

PMCID: PMC6106018 PMID: 30174893

2. Sobnach S, Nicol A, Nathire H, Kahn D, Navsaria P. Management of the retained knife blade. World J Surg. 2010Jul; 34(7):1648-52. https://doi.org/10.1007/s00268-010-0514-4 
PMID: 20195600

3. Isenburg $\mathrm{S}$, Jackson $\mathrm{N}$, Karmy-Jones $\mathrm{R}$. Removal of an impaled knife under thoracoscopic guidance. Can Respir J.2008;15(1):39-40. https://doi.org/10.1155/2008/452421

PMCID: 2677854 PMID:18292852

4. Ashok V, Francis J. A practical approach to adult one-lung ventilation. Bja Education. 2018 Mar1; 18(3):69-74. https://doi.org/10.1016/j.bjae.2017.11.007

5. Maruyama D, Chaki T, Omote M, Hirata N, Yamauchi M, Yamakage M. Movements of the double-lumen endotracheal tube due to lateral position with head rotation and tube fixation: a Thiel-embalmed cadaver study. Surgical and Radiologic Anatomy. 2015 Sep 1; 37(7):841-4. https://doi.org/10.1007/s00276-014-1411-6 PMID: 25542246

6. Khan MF, Khan FA, Minai FN. Airway management and hemodynamic response to laryngoscopy and intubation in supine and left lateral positions. Middle East J Anaesthesiol. 2010 Oct; 20(6):795-802.

PMID: 21526663
7. Nathanson MH, Gajraj NM, Newson CD. Tracheal intubation in a manikin: comparison of supine and left lateral positions. BJA: British Journal of Anaesthesia. 1994 Nov 1; 73(5):690-1.

8. Ron M. Walls MFFF. Intubation in the Lateral Position: Tube or LMA? NEJM J Watch [Internet]. 2005 Dec 21 [cited 2020 Dec 11];2005. Available from: https://www.jwatch.org/EM200512210000005/ 2005/12/21/intubation-lateral-position-tube-or$\operatorname{lma}$

9. Naithani, M., Saxena, K.N., Dua, C. and Gaba, P., 2012. Comparison of Trachlight TM guided tracheal intubation in the lateral position versus the supine position. Sri Lankan Journal of Anaesthesiology, 20(1), pp.13-17. https://doi.org/10.4038/slja.v20i1.3500

10. Kumar A, Saha KK, Jagiasi B, Saha KK. A novel technique of anesthesia induction in supine position with impaled knife in the back. Annals of cardiac anaesthesia. 2015 Apr; 18(2):231. https://doi.org/10.4103/09719784.154484 PMID: 25849698 PMCID: 4881622 